\title{
O Sistema De Contagem Guarani: Caminhos Para A Prática Pedagógica
}

\section{The Guarani Counting System: Pathways To Pedagogical Practice}

\author{
Sérgio Florentino da Silva \\ Instituto Federal de Santa Catarina - (IFSC)
}

\begin{abstract}
Resumo
Em Santa Catarina há 21 aldeias indígenas Guarani e, entre elas, incluem-se a Aldeia Itaty do Morro dos Cavalos e a Aldeia M'Biguaçu. Entre os grandes desafios dessas comunidades destacam-se o desejo em revitalizar seus conhecimentos tradicionais e, além disso, associá-los aos conhecimentos acadêmicos para que, dessa forma, possam entender outras culturas e interagir de forma mais efetiva com elas. Neste sentido, temos como objetivo deste artigo analisar os aspectos básicos do sistema de contagem desses indígenas, tais como, linguagem oral, símbolos gráficos e contagem manual, identificando as relações que esses possuem com os conhecimentos matemáticos acadêmicos. Além disso, propomos atividades que possam possibilitar a articulação entre essas duas formas de conhecimento. As discussões apresentadas nesse trabalho representam parte da pesquisa de Silva (2011) que, norteado pela metodologia Estudo de Caso do Tipo Etnográfico, realizou uma pesquisa na perspectiva teórica da Etnomatemática junto a líderes das comunidades Guarani das Aldeias Itaty e M'Biguaçu.
\end{abstract}

Palavras-chave: Sistema de contagem Guarani. Etnomatemática Guarani. Educação Escolar Indígena.

\begin{abstract}
There are 21 indigenous Guarani tribes in Santa Catarina, among which are the Itaty Tribe located at Morro dos Cavalos and M'Biguaçu Tribe. Among the biggest challenges of these communities is the desire to revive their traditional knowledge and, in addition to it, to link it to academic knowledge so that, this way, they can understand other cultures and interact more effectively with them. Consequently, we aim to analyze the basic aspects of the counting system of these Indigenous Tribes, such as oral language, graphic symbols and manual counting; identifying the relations they have with academic mathematical knowledge. In addition, we propose activities that may enable the articulation between these two forms of knowledge. The discussions presented in this paper represent part of the research done by Autor (2011), which, guided by the Ethnographic Case Study methodology, carried out a research in the theoretical perspective of Ethnomathematics along with leaders of the Guarani communities of Itaty and M'Biguaçu.
\end{abstract}

Keywords: Guarani counting system. Guarani Ethnomathematics. Indigenous School Education.

\section{Introdução}

Desde o processo de expansão colonial as formas de conhecimento dos povos colonizados, incluindo os saberes de práticas matemáticas, foram consideradas pelos colonizadores como inferiores e sem valor o que implicou um acelerado processo de 
"esquecimento" da cultura dos colonizados. Os indígenas do Brasil colonial, por exemplo, foram submetidos a uma educação escolar " [...] em que o objetivo das práticas educativas era negar a diversidade dos índios, ou seja, aniquilar culturas e incorporar mão-de-obra indígena à sociedade nacional" (FERREIRA, 2001, p. 72).

Em Santa Catarina há 21 aldeias indígenas Guarani ${ }^{1}$ e, entre elas, incluem-se a Aldeia Itaty do Morro dos Cavalos e a Aldeia M’Biguaçu situadas nos municípios de Palhoça e Biguaçu, respectivamente - grande Florianópolis. Essas aldeias estão localizadas às margens da Rodovia BR-101, sendo a primeira no Km 235 e a segunda no Km 190.

Depois de mais de três anos de pesquisa junto a essas duas aldeias, o que inclusive resultou na dissertação de Silva (2011), constamos a necessidade desse povo em revitalizar seus conhecimentos tradicionais e associá-los aos conhecimentos acadêmicos. Dessa forma, ampliando e melhorando a interação entre esses diferentes conhecimentos. Ao encontro dessa demanda, recaímos no sistema de contagem Guarani e verificamos que se trata de um rico sistema.

Neste artigo temos como objetivo analisar os aspectos básicos do sistema de contagem Guarani, com foco na linguagem oral, símbolos gráficos e contagem manual, e suas relações e entrelaçamentos com o sistema matemático acadêmico. Além disso, traremos propostas de atividades que articulam esses dois sistemas, buscando atender as necessidades do Guarani no que concerne a revitalização e a associação entre os conhecimentos tradicionais e acadêmicos.

Nosso estudo teve como referencial teórico os pressupostos do Programa Etnomatemática que discutiremos na seção seguinte. Metodologicamente se trata de um Estudo de Caso do tipo Etnográfico. Segundo André (2008, p. 31),

[...] pode-se dizer que o estudo de caso tipo etnográfico em educação deve ser usado quando: (1) há interesse em conhecer uma instância em particular; (2) pretende-se compreender profundamente essa instância em sua complexidade e totalidade; e (3) busca-se retratar o dinamismo de uma situação numa forma muito próxima do seu acontecer natural.

O estudo etnográfico é realizado, de forma recorrente, na Antropologia e na Educação, todavia, há uma diferença de enfoque entre as pesquisas realizadas nessas duas áreas. No primeiro caso, tradicionalmente, os antropólogos fazem etnografia tendo como objetivo descrever a cultura (práticas, hábitos, crenças, valores, linguagens, significados, dentre outros) de um grupo social. No caso dos pesquisadores em Educação, a preocupação central é com o processo educativo e, por isso, a Educação faz estudo de caso do tipo etnográfico e não

\footnotetext{
${ }^{1}$ Seguindo a "Convenção para Grafia dos Nomes Tribais", escreveremos os nomes indígenas sem flexão de gênero e de número.
} 
etnografia no seu sentido estrito. Trata-se de uma adaptação da etnografia à Educação. Essa adaptação permite que certos requisitos subjacentes à Antropologia, como por exemplo, longa permanência do pesquisador em campo e uso de amplas categorias sociais na análise de dados, não sejam cumpridos criteriosamente. (ANDRÉ, 2008).

Por se tratar de um estudo de caso, as considerações que faremos dizem respeito apenas ao sistema de contagem dos Guarani das Aldeias Itaty e M'Biguaçu. Neste sentido, utilizamos várias técnicas de coleta de dados, tais como fotos, gravações em áudio, entrevistas, transcrições e anotações no diário de campo. ${ }^{2}$

\section{Participantes Da Pesquisa}

Um dos critérios de escolha dos participantes da pesquisa, foi buscar pessoas que se relacionavam tanto na cultura indígena quanto na não indígena e que, possivelmente, compartilhavam os conhecimentos tradicionais indígenas e os conhecimentos de outros segmentos da sociedade nacional. Dessa forma, concebemos que nossa compreensão a respeito dos conhecimentos indígenas seria mais fácil. Preferencialmente, os envolvidos na pesquisa deveriam, de alguma forma, participar efetivamente do cotidiano das aldeias. Assim, em diálogo com a comunidade, concordamos que os participantes seriam os professores indígenas e não indígenas das escolas das aldeias. Sendo assim, compomos nossa amostra de participantes com os seguintes indivíduos: Adão Antunes (Karaí Tataendy), Wanderley Moreira (Karai Ivyju Miri), Geraldo Moreira (Karai Okenda) e Santiago de Oliveira.

Adão (in memoriam) morou na Aldeia Itaty do Morro dos Cavalos. Foi professor Guarani da Escola Indígena (EI) Itaty e da EI KaaKupe, da comunidade indígena do Massiambu - próxima à Aldeia Itaty do Morro dos Cavalos. Também foi pesquisador da história indígena Guarani e autor do livro Antunes (2008).

Os demais indígenas residem atualmente na Aldeia M'Biguaçu e trabalham na coordenação e na docência na EI Whera Tupã-Poli TotyDja localizada junto a essa aldeia. Wanderley pesquisou a etnomatemática Guarani por mais de cinco anos junto à grande liderança religiosa, espiritual e xamã da comunidade, o Karai Alcindo Moreira Werá Tupã que é considerado, pelos próprios indígenas, uma pessoa de grande sabedoria para os Guarani. Geraldo é pesquisador da cultura Guarani. Santiago, por sua vez, está pesquisando a matemática usada pelos Guarani atualmente.

\footnotetext{
${ }^{2}$ Os dados foram coletados entre 2008 e 2011.
} 
Os três primeiros indígenas apresentados são líderes de suas comunidades e foram discentes da UFSC no Curso de Licenciatura Intercultural Indígena do Sul da Mata Atlântica. Wanderley e Geraldo, após sete anos sendo orientados pelo Karai Alcindo, concluíram seu trabalho de conclusão de curso (TCC).

\section{O Programa Etnomatemática}

Ao longo da história, as concepções subjacentes ao conhecimento matemático foram motivo de muitas reflexões e discordâncias por parte de filósofos e de matemáticos, sendo difícil e não desejável estabelecer um consenso. Nesse processo, incluem-se aqueles que concebem a existência de apenas uma forma de matemática chamada de matemática universal. Em oposição a essa compreensão, está o Programa Etnomatemática, que entende que “[...] existem formas culturalmente distintas de manejar quantidades, números, medidas, formas e relações geométricas" (FERREIRA, 1998, p. 7). Consequêntemente, a matemática é considerada uma produção humana e histórica.

De maneira ampla, D’Ambrósio (2005, p. 30) afirma que “[...] as ideias matemáticas, particularmente comparar, classificar, quantificar, medir, explicar, generalizar, inferir e, de algum modo, avaliar, são formas de pensar, presentes em toda espécie humana”. Essas formas, porém, têm significados, linguagens e uso que são diferentes de acordo com a cultura que estão inseridos. A citação seguinte, elaborada por D’Ambrósio (2006, p. 286), contribui para o debate a respeito das ideias que circundam a etnomatemática. De acordo com esse pesquisador,

$\mathrm{Na}$ pretensão de expressar essas idéias [sobre etnomatemática] em uma palavra, decidi arriscar um abuso etimológico, introduzindo o neologismo etno-matemá-tica. Recorrendo, obviamente com limitada competência, ao grego e, certamente, motivado pelas minhas preocupações históricas e filosóficas com a natureza e o significado da matemática, decidi usar, para 'artes e técnicas', a palavra technée a grafia aproximada tica. Para 'entender, explicar, lidar com' utilizei, abusivamente, mathema, ou matema, o que provocou reações, esperadas, dos especialistas na língua grega. E para 'ambiente natural, social e cultural', usei o óbvio ethno, ou etno. O abuso foi além e ampliei o sentido de etno para incluir 'próximo ou distante'. E a menção, muito importante, à assunção, pela espécie humana, 'seu direito e capacidade' de modificar o ambiente natural, social e cultural, está implícito, com maior ou menor visibilidade e intensidade, em todos os mitos de criação. Daí surgiu etno-matema-tica. Uma parte da crítica focalizou o fato de que matemática não reflete a etimologia de 'matemática', que, no sentido usado a partir da Baixa Idade Média e do Renascimento, é também um neologismo. Realmente, o matema, que é uma das raízes etimológicas da palavra etnomatemática, tem pouco a ver com 'matemática'. (grifo do autor). 
Em campo, Ferreira (1994, p. 91) usa o Programa Etnomatemática de forma a respeitar ao máximo a cultura investigada e, segundo ele, esse Programa "[...] é uma tentativa permeada pela busca dos mitos compartilhados que sejam matematicamente significativos [...]". Nessa busca, pode-se melhor compreender a matemática de um povo e, consequentemente, respeitála. Nesse caminho Scandiuzzi (2009, p. 19) nos alerta para o fato de que,

[...] quando conhecemos a matemática de um grupo social culturalmente identificável, ele passa a fazer parte de nós e seus hábitos e costumes serão respeitados, não serão folclore nem tidos como 'menores', necessitando de uma reeducação.

Assim, defendemos, neste artigo, uma base teórica para a Etnomatemática no sentindo dambrosiano, em que a Matemática pode ser percebida como a arte ou a técnica de conhecer e entender os saberes de quantificação, números, medidas, formas e relações geométricas de determinada cultura e que o que é ensinado pela cultura escolar é uma dessas artes ou técnicas. Além disso, o Programa Etnomatemática na Educação Escolar Indígena, de forma institucionalizada e intencional, pode transformar situações cotidianas em propostas pedagógicas interligando-as com outras formas de saber.

\section{O Sistema De Contagem Guarani}

Esta seção é dedicada à teorização das dimensões do sistema de contagem Guarani, não de forma ampla, mas sobre os três aspectos que este artigo aborda, a saber, aspectos gerais; linguagem oral; símbolos gráficos.

\subsection{Aspectos Gerais}

A principal base de contagem Guarani é cinco $^{3}$ e há dois motivos que justificam por que constituir grupos de cinco elementos na contagem: o número de dedos de uma mão, que geralmente é cinco, e o caule da mandioca. Com relação à mandioca observe a Figura 1 e note que o caule possui vários caroços em sua superfície.

\footnotetext{
${ }^{3}$ Os Guarani também contam de maneira a constituir grupos de vinte e de vinte e cinco elementos. Ler Silva (2011).
} 


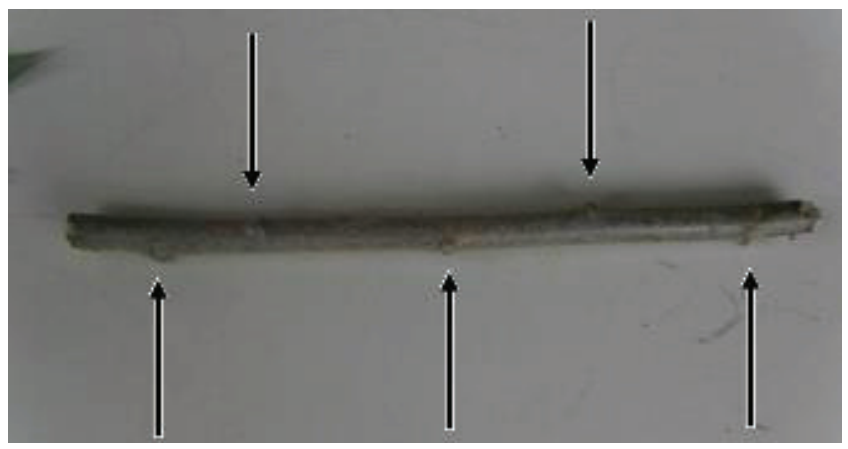

Figura 1: A organização do caule da mandioca Fonte: Silva (2011, p. 74)

Para fazer uma plantação de mandioca os Guarani costumam cortar o caule em pequenas partes de maneira que cada parte é seccionada a cada grupo de cinco caroços. Depois de feita a seção, cada pedaço é enterrado. Nesse contexto, é recorrente a prática de contar em grupos de cinco elementos o que justifica a base cinco na contagem.

Mesmo não sendo mais tão utilizada como antigamente, os Guarani possuem uma forma de contar manualmente em que se busca dispor os dedos de forma a constituir pares dentro de cada mão, ou seja, num conjunto com cinco elementos se constitui pares. Para ilustrar essa afirmação, veja o quadro 1 .

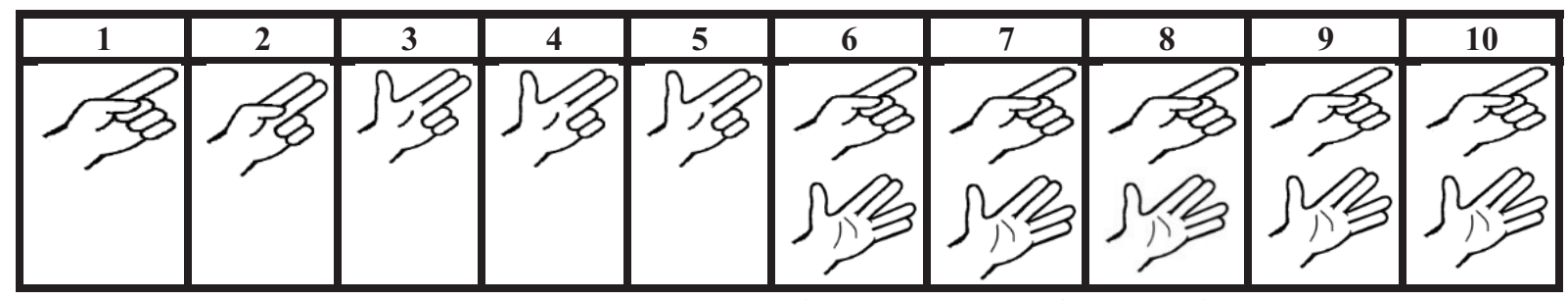

Quadro 1: Representação manual para a contagem de um até dez Fonte: Silva (2011, p. 76)

Já dissemos que os Guarani contam preferencialmente de modo a constituir grupos de cinco elementos. Consequentemente, na representação manual de seis os dedos de duas mãos diferentes não se juntam a fim de constituírem um par de dedos, pois, assim, estaríamos formando grupos de seis elementos e contrariaríamos a citada preferência. Portanto, a tendência em formar pares ocorre dentro de um conjunto de cinco elementos. Essa tendência em formar pares na contagem se deve ao fato de que diversas coisas, para esses indígenas, se constituem aos pares: o sol e a lua; o homem e a mulher; as duas orelhas.

Como vemos, a preferência pela base cinco além da tendência em formar pares dentro de um conjunto com cinco elementos não é sem motivo. A escolha pela base cinco é justificada pela maneira como os Guarani percebem e lidam com o mundo que estão inseridos. Já a tendência por formar pares está relacionada à maneira como os Guarani concebem a constituição das coisas. 


\subsection{A linguagem Oral}

A partir do diálogo com os participantes da pesquisa, que consideram o agrupamento de cinco em cinco e a formação de pares, discutidos na subseção anterior, interpretamos que petẽ quer dizer um só ou não tem par, mokoũ quer dizer um par, mboapy é o início de um novo par, irundy quer dizer dois pares e peteĩ niruĩ significa que acabou a contagem ou um sem par. Dessa forma, inferimos as correlações do quadro 2 a seguir:

\begin{tabular}{|c|c|}
\hline Números na língua portuguesa & Números na língua Guarani \\
\hline Um só ou não tem par & pete $\tilde{i}$ \\
\hline Dois (um par) & mokoĩ \\
\hline Três (inicio de um novo par) & Mboapy \\
\hline Quatro (dois pares) & Irundy \\
\hline Cinco (acabou a contagem ou um sem par) & pete $\tilde{i}$ nirui $\tilde{i}^{4}$ \\
\hline
\end{tabular}

Quadro 2: Linguagem Guarani dos primeiros cinco números Fonte: Silva (2011, p. 79)

Na constituição dos números do quadro 2 vemos que caso o número cinco fosse definido como o começo de um novo par estaríamos pensando em formar um par entre os números cinco e seis, ou seja, formaríamos pares dentro de um conjunto de seis e não de cinco elementos o que é contraditório a tendência de agrupar de cinco em cinco. Por esse motivo, segundo as regras Guarani que discutimos, o número cinco não é definido como começo de um novo par.

O quadro 3 a seguir sintetiza a linguagem Guarani do número 6 até o número 24 .

\begin{tabular}{|c|c|}
\hline Números na língua portuguesa & Números na língua Guarani \\
\hline seis & petei nirui pete $\tilde{i}$ \\
\hline sete & 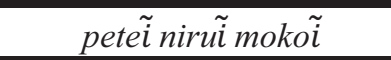 \\
\hline oito & 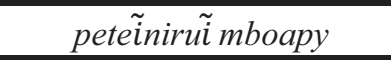 \\
\hline nove & peteïniruĩ irundy \\
\hline dez & 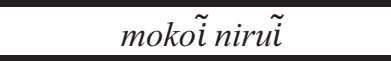 \\
\hline onze & 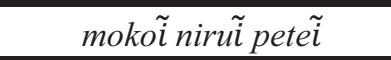 \\
\hline doze & 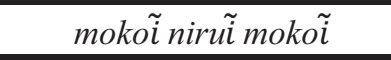 \\
\hline treze & mokoĩ niruĩ mboapy \\
\hline quatorze & 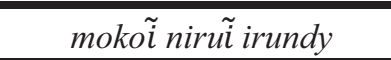 \\
\hline quinze & Mboapy nirui \\
\hline dezesseis & Mboapy nirui petẽ \\
\hline dezessete & Mboapy niruĩ moko $\tilde{i}$ \\
\hline dezoito & Mboapy niruĩ mboapy \\
\hline dezenove & Mboapy niruĩ irundy \\
\hline vinte & Irundy nirui \\
\hline
\end{tabular}

\footnotetext{
${ }^{4}$ A escrita dos números usada em todo este artigo é idêntica à usada pelo senhor Adão Antunes.
} 


\begin{tabular}{|c|c|}
\hline Vinte e um & Irundy niruĩ pete $\tilde{i}$ \\
\hline vinte e dois & 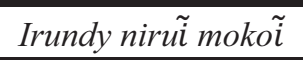 \\
\hline vinte e três & Irundy niruĩ mboapy \\
\hline vinte e quatro & Irundy nirui irundy \\
\hline
\end{tabular}

Quadro 3: Linguagem Guarani dos números seis até vinte e quatro Fonte: Silva (2011, p. 82)

Para compor a linguagem dos múltiplos de cinco dos Quadros 2 e 3 - cinco, dez, quinze e vinte - é necessário saber que esses números podem ser obtidos como o produto de dois números naturais em que um dos fatores é cinco. Assim, buscando constituir grupos de cinco, é preciso saber que $5=1 \times 5,10=2 \times 5,15=3 \times 5$ e $20=4 \times 5$. A partir desses conhecimentos aritméticos, a linguagem desses números é constituída obedecendo a seguinte regra: escreve-se primeiro a linguagem do primeiro fator - petẽ̃, mokoĩ, mboapy, irundy (respectivamente um, dois, três ou quatro) - seguida da palavra nirũ̃ (significa não tem par).

Com relação aos demais números do Quadro 3, é necessário saber que cada um deles pode ser obtido como uma soma de duas parcelas, em que a primeira deve ser um número múltiplo de cinco e a outra deve ser o número um, dois, três ou quatro. Dessa forma, constituemse os números com a seguinte regra: escreve-se primeiro a linguagem da primeira parcela (múltiplo de cinco) - peteĩ niruĩ, mokoũ niruĩ, mboapy niruĩ, irundy niruĩ (respectivamente cinco, dez, quinze e vinte) - seguida da linguagem da segunda parcela - petẽ̃, mokoũ, mboapy, irundy. Para escrever o número vinte e três, por exemplo, é necessário saber que $23=4$ x $5+3$ para, então, poder expressar a linguagem irundy niruĩ mboapy.

\subsection{Os Símbolos Gráficos}

Já comentamos anteriormente que para fazer uma plantação de mandioca, os Guarani costumam cortar o caule em pequenas partes de maneira que cada uma delas seja seccionada a cada grupo de cinco caroços. Além disso, de acordo com a percepção deles, o caule da mandioca possui vários caroços que se alinham a cada conjunto de cinco caroços, ou seja, o primeiro e o quinto caroço estão contidos num segmento de reta. ${ }^{5}$ Por isso, eles representam o número um como uma pequena circunferência, referindo-se a um dos caroços da mandioca, e o número cinco como um segmento de reta. Com o agrupamento de circunferências (unidades) e segmentos de reta (cinco) constituem-se os símbolos gráficos dos quadros 4 e 5 a seguir.

\footnotetext{
${ }^{5}$ Não desejamos afirmar que todos os caules de mandioca têm essa organização. Queremos apenas destacar que se trata de um conhecimento compartilhado pelos Guarani.
} 


\begin{tabular}{|c|c|c|c|c|c|c|c|c|c|c|c|}
\hline 1 & 2 & 3 & 4 & 5 & 6 & 7 & 8 & 9 & 10 & 11 & 12 \\
\hline $\mathrm{O}$ & $\mathrm{OO}$ & $\mathrm{OOO}$ & $\mathrm{OOOO}$ & L & $\mathrm{O}$ & $\mathrm{OO}$ & $\mathrm{OOO}$ & $\mathrm{OOOO}$ & & $\mathrm{O}$ & $\mathrm{OO}$ \\
\hline
\end{tabular}

\begin{tabular}{|c|c|c|c|c|c|c|c|c|c|c|c|}
\hline 13 & 14 & 15 & 16 & 17 & 18 & 19 & 20 & 21 & 22 & 23 & 24 \\
\hline $\mathrm{OOO}$ & OOOO & $=$ & $\mathrm{O}$ & $\mathrm{OO}$ & $\mathrm{OOO}$ & $\mathrm{OOOO}$ & $\longrightarrow$ & $\mathrm{O}$ & $\mathrm{OO}$ & $\mathrm{OOO}$ & OOOO \\
\hline
\end{tabular}

Quadro 5: Símbolos gráficos dos números 13 até vinte e quatro Fonte: Silva (2011, p. 102)

Em Silva (2011) ainda encontramos criativas maneiras de expressar, oralmente e graficamente, números maiores do que os que aqui analisamos.

\section{Caminhos Para A Prática Pedagógica}

Nesta seção discutiremos caminhos viáveis e com algumas possibilidades de inserção do sistema de contagem Guarani nas escolas indígenas das Aldeias de Palhoça e Biguaçu. Antes de estudar o sistema indo-arábico, propomos o estudo de alguns aspectos do sistema Guarani. Dessa forma, espera-se contribuir para a revitalização dos conhecimentos tradicionais e contribuir para a aprendizagem do sistema indo-arábico. Pretendemos também, como consequência do processo de aprendizagem, que os alunos desenvolvam a concepção de que a etnomatemática Guarani está associada a cultura Guarani.

\subsection{Sistema De Contagem Manual Dos Guarani: Propostas De Atividades}

A fim de que os alunos desenvolvam as noções iniciais sobre o sistema de contagem manual Guarani, propomos, na primeira atividade, que eles pesquisem, junto aos mais velhos, como é (era) a contagem manual. Para que tal objetivo seja atingido, sugerimos que os alunos façam perguntas similares às destacadas a seguir:

1. Como é (era) o sistema de contagem manual dos mais antigos? Faça desenhos ilustrativos para facilitar sua explicação.

2. Os mais antigos contavam de maneira a agrupar os dedos em conjuntos de quantos elementos? 
3. Qual o motivo faz com que a contagem Guarani seja da maneira dita na questão b? Esse motivo tem alguma relação com o modo de ser Guarani?

4. As pessoas mais velhas ainda contam - com mãos - da maneira tradicional?

5. Você usa essa maneira para contar?

6. Faça desenhos que mostrem coisas, animais, plantas, pessoas do cotidiano Guarani dispostos aos pares.

7. Crie uma pequena história em quadrinhos que apresente indígenas em situações cotidianas - trabalhos domésticos, brincadeiras,... - contando com as mãos da maneira tradicional. Exponha as histórias em cartazes.

8.

Num segundo momento, já na sala de aula, os resultados de pesquisa serão discutidos. Deve-se estimular que os alunos exponham suas ideias sem deixar de mencionar qual a fonte de sua pesquisa.

\subsection{A Linguagem Oral Do Sistema De Contagem Guarani: Proposta De Atividade}

A atividade que agora expomos busca revitalizar a linguagem oral do sistema de contagem Guarani. Após seu término, esperamos que os alunos entendam que os significados dos termos peteĩ, mokoĩ, mboapy e peteĩ nirui estão associados à formação de pares. Propomos a seguinte pergunta:

1. Qual o significado dos termos petei, mokoí, mboapy e petei nirui ?

Depois que essa questão for discutida adequadamente, provavelmente, a maior parte dos alunos entenderá que a linguagem Guarani está associada à forma de contar - constituindo pares - e, desta maneira, relaciona-se ao modo de ser Guarani. Após essa questão inicial, pode-se discutir os demais números do Quadro 3.

\subsection{Símbolos Gráficos Do Sistema De Contagem Guarani: Propostas De Atividades}

Essa atividade busca revitalizar tanto os símbolos gráficos do sistema Guarani quanto o significado e a importância de objetos de uso cotidiano. Para tanto, os alunos devem pesquisar com os mais velhos como são (eram) representados os números de 1 a 24 . Para que tal objetivo 
seja alcançado os alunos devem elaborar perguntas similares as propostas a seguir.

1. Como se escreve, na maneira Guarani, os números de 1 a 5?

2. Esses símbolos surgem de algo do cotidiano Guarani - alimentos, animais, artesanato,...?

3. Usando os símbolos Guarani, represente os números de 1 a 24. Faça os desenhos partindo dos menores para os maiores números.

4. Existe alguma vantagem em representar 25 com 5 "pedacinhos de reta" e não com 25 "bolinhas"? Com seus colegas, discuta essa questão.

Para evidenciar a contagem de objetos do cotidiano Guarani, o professor pode desenhar conjuntos de objetos como chocalhos, colares, petecas, pamonhas, espigas de milho, entre outros. Ao lado de cada figura, os alunos devem escrever o nome das coisas que formam os conjuntos e o número de objetos de cada conjunto. Nessa atividade, use os símbolos gráficos do sistema Guarani. Sobre o chocalho, pode-se discutir o uso desse objeto nos rituais sagrados. Sobre os colares pode-se discutir o seu significado no fortalecimento do espírito. A peteca pode ser discutida como instrumento para uso no lazer. Com a pamonha pode-se discutir sobre a culinária, a maneira de como é feita. Sobre as espigas de milho, pode-se discutir a diversidade de sementes ${ }^{6}$, suas diferenças e semelhanças.

Ao término dessas atividades, espera-se que os alunos saibam que os símbolos dos números de 1 a 5 estão associados ao caule da mandioca e que fixem os símbolos gráficos Guarani. Com relação à questão 4 dessa atividade, se espera que os alunos entendam que representar o número 5 com um "pedacinho de reta" e não com 5 "bolinhas" torna-se mais prático. Consequentemente, também é mais prático representar os números 10, 15, 20 e 25 . Além da questão prática, deve-se destacar que apenas um símbolo pode representar a quantidade 5.

\subsection{Contagem Com O Uso Do Ajaka, Pedrinhas E O Caule Da Mandioca: Propostas De} Atividades

A atividade lúdica a seguir deverá fixar a ideia de que apenas um símbolo, no caso de um pedaço de mandioca, pode representar um conjunto de outros. Sabemos que essa noção é

\footnotetext{
${ }^{6}$ A discussão sobre esses objetos do cotidiano Guarani pode ser encontrada em Antunes (2008).
} 
essencial para o entendimento do conceito de dezena e centena. Para tanto, devem-se trazer alguns ajaka (balaios), um conjunto de objetos do cotidiano dos alunos a serem contados, pedrinhas e pedaços de caules de mandioca cortados em conjunto de cinco caroços. Os alunos terão a tarefa de contar objetos a partir da seguinte regra:

1. A cada objeto contado uma pedra deverá ser colocada no ajaka;

2. Quando completar um conjunto de 5 pedras, essas deverão ser retiradas do ajaka e substituídas por um pedacinho do caule de mandioca.

Para exercitar as operações básicas da matemática fazendo uso de elementos da cultura Guarani, propomos que a atividade anterior seja feita em ordem inversa. Assim, o professor deve apresentar aos alunos vários ajaka com o seu interior contendo pedrinhas e pedaços de caule de mandioca. Aos alunos é definida a seguinte tarefa:

3. Supondo que uma pedrinha represente a unidade e que um pedaço de mandioca represente 5, observe os ajaka e determine quantos objetos foram contados em cada ajaka.

As atividades propostas acima podem ser feitas contando diferentes quantidades de objetos. Ao observar um ajaka com 3 pedaços de mandioca e 4 pedrinhas, por exemplo, o aluno deverá saber que $3 \times 5+4=19$.

\subsection{As Relações De Reciprocidade Guarani E O Dinheiro: Propostas De Atividades}

Conforme é sabido, tradicionalmente o sistema econômico Guarani é baseado nas relações de reciprocidade (troca). No entanto, a situação de contato com a cultura não indígena exige que os Guarani aprendam a lidar com o dinheiro, principalmente na venda de artesanatos. Visando o fortalecimento da relação do Guarani com o dinheiro, necessidade nos dias atuais, e, consequentemente, permitir que os alunos entendam que um símbolo pode ter o mesmo valor de um conjunto de outros, propomos as seguintes atividades:

1. Na cultura Guarani, a produção se destina a satisfazer as necessidades do grupo familiar e não o lucro financeiro. O sistema econômico é feito através de troca e distribuição entre as famílias nucleares e, portanto, concretiza-se, sobretudo na produção de alimentos. Pesquise 
junto aos mais velhos como é a relação de reciprocidade presente no sistema econômico Guarani. Como se dá essa relação na produção de uma roça? Qual é a sua importância na cultura Guarani?

2. Por que os Guarani, atualmente, usam dinheiro?

Na sequência, o professor deve dizer que o sistema monetário brasileiro é baseado na moeda corrente que é o real. Logo após, apresenta as notas e moedas de real e as relações entre essas notas e moedas. Para praticar as relações presentes no sistema monetário brasileiro, propomos as seguintes atividades:

1. Considere que um ajaka seja vendido ao preço de 5 reais. Uma pessoa que deseja comprar o ajaka com moedas de um real deverá dar quantas moedas?

2. Considere que um ajaka seja vendido ao preço de 10 reais. Uma pessoa que deseja comprar o ajaka com moedas de um real deverá dar quantas moedas?

3. Considere que um ajaka seja vendido ao preço de 1 real. Uma pessoa que deseja comprar o ajaka com moedas de um 10 centavos deverá dar quantas moedas?

4. Considere que um ajaka seja vendido ao preço de 2 reais. Uma pessoa que deseja comprar o ajaka com moedas de um real deverá dar quantas moedas?

5. Considere que um ajaka seja vendido ao preço de 10 reais. Uma pessoa que deseja comprar o ajaka com notas de 2 reais deverá dar quantas moedas?

6. Considere que um ajaka seja vendido ao preço de 5 reais. Se uma pessoa dispõe de moedas de um real e notas de dois reais, qual o menor número de notas e moedas que precisam ser usados?

\subsection{Contagem Com O “Homem De Contar": Propostas De Atividades}

A atividade a seguir utilizará outra maneira de contar. Ela exige a participação de um aluno, que será chamado de "homem de contar", e de objetos do cotidiano Guarani a serem contados. Para que esse sistema seja executado, o "homem de contar" deve proceder da seguinte forma: 
1. A cada objeto contado, levante um dedo ${ }^{7}$. Depois que todos os dedos das mãos estiverem levantados, feche todos os dedos. Na sequência, levante um a um os dedos a cada objeto contado. Caso o "homem de contar" tenha esticado todos os dedos das mãos 3 vezes, por exemplo, significa que foram contados 3 x 10 objetos, ou seja, 30 objetos.

Depois que essa atividade lúdica for realizada algumas vezes, com diferentes quantidades de objetos contados, os alunos devem perceber que é necessário memorizar quantas vezes o "homem de contar" levantou todos os dedos e retomou o procedimento de contagem. Para resolver o problema da exigência de memória, propomos que novos alunos sejam "homens de contar" depois que todos os dedos das mãos estejam levantados. Essa regra será definida da seguinte maneira:

2. Com a ajuda de novos companheiros, após se esgotarem os dedos das mãos do primeiro "homem de contar", um segundo homem passa a contar levantando os dedos das mãos. Após se esgotarem todos os dedos das mãos do segundo, um terceiro homem entra em ação e depois um quarto homem e assim por diante. A contagem de 36, por exemplo, terá 3 "homens de contar" com todos os dedos levantados e mais um homem com seis dedos levantados ${ }^{8}$.

Com a atividade anterior, o professor deve estimular os alunos a notarem que a quantidade de objetos contados é obtida pela adição das quantidades de dedos levantados de todos os "homens de contar". Como a operação de adição é comutativa e associativa, o sistema de contagem agora usado não é posicional. Na prática, implica dizer que não faz diferença um "homem de contar" estar numa fileira ou em outra.

Ainda fazendo uso dos "homens de contar", pode-se desenvolver nos alunos a noção de valor posicional. Para tanto, o professor, fazendo uso dos "homens de contar", deve mudar as regras de contagem da seguinte forma:

3. Todos os "homens de contar terão posições fixas e estarão dispostos lado a lado. Iniciase a contagem com o "homem de contar" da direita. Cada vez que o primeiro homem levantar seus dez dedos, o segundo homem deve levantar um dos seus. Assim que o segundo homem

\footnotetext{
${ }^{7}$ Da mesma maneira que na cultura Guarani, sugiro que os "homens de contar" sempre levantem os dedos de maneira a constituir pares.

${ }^{8}$ Procedimentos como esses foram encontrados em desenhos feitos nas cavernas no período da Média Idade da Pedra (GUNDLACH, 1992).
} 
levantar um de seus dedos, o primeiro homem deve baixar todos os seus. O procedimento deve seguir de tal forma que cada vez que o segundo homem levantar os seus dez dedos, um terceiro homem deve levantar um de seus dedos e assim por diante. Para contar 31, por exemplo, no final da contagem o primeiro "homem de contar" estará com um dedo levantado enquanto que o segundo terá três dedos levantados. Cabe salientar que durante toda a contagem de 31 , o primeiro "homem de contar" levantou os dedos 31 vezes.

Com essa atividade se espera que os alunos percebam que um dedo levantado do segundo homem equivale a "memória-registro" do levantamento de dez dedos do primeiro homem. De maneira análoga, um dedo levantado do terceiro homem equivale a "memória-registro" do levantamento de dez dedos do segundo, ou cem dedos do primeiro homem. Com isso é possível, ainda, definir dezena e centena.

Na sequência, essa atividade pode ser feita em sentido inverso, ou seja, o professor, depois de desenhar alguns "homens de contar", pode perguntar aos seus alunos quantos objetos foram contados.

Depois que as duas atividades forem suficientemente praticadas, com diferentes quantidades de objetos contados, o professor pode discutir a relação da posição do "homem de contar" com os valores contados. Neste caso, dependendo da posição de um "homem de contar" o levantamento de um dedo pode ter um valor diferente na contagem. Assim, diz-se que esse sistema é posicional.

\subsection{Atividades Lúdicas: "Nunca Dez", "Nunca Cinco" E "Nunca Dois": Propostas De Atividades}

Para estimular o uso de objetos do cotidiano do Guarani, podem-se substituir os "homens de contar" por ajaka e pedrinhas. Para contar, são colocados vários ajaka lado a lado de tal maneira que a cada objeto contado uma pedrinha é colocada no ajaka da direita. Ao completar dez pedrinhas, todas deverão ser substituídas por uma única pedrinha colocada do ajaka ao lado do primeiro. Em seguida, procede-se da mesma maneira que a atividade anterior. Para facilitar a aplicação dessa atividade lúdica, sugeriremos que ela deva ser chamada de "nunca dez"9.

Para exercitar o uso de outras bases, pode-se, de maneira análoga a atividade "nunca dez", fazer a atividade "nunca cinco" e "nunca dois", por exemplo.

Após o encerramento dessa atividade, o professor pode fazer a atividade em ordem

\footnotetext{
${ }^{9}$ Tomamos esse termo de Tinoco (2001, p. 236).
} 
inversa. Para tanto, deve-se colocar, por exemplo, dois ajaka lado a lado com uma pedrinha no segundo e duas no primeiro. Assim, pode-se perguntar aos alunos quantos objetos foram contados para que os ajaka estivessem com esses números de pedrinhas em seu interior. Conforme se sabe, se a regra for "nunca dois" o resultado será diferente do resultado se a regra for "nunca cinco".

A partir das atividades até aqui propostas, o sistema de numeração indo-arábico pode ser formalizado.

\subsection{Operação De Adição E Subtração Com Objetos Do Cotidiano Guarani: Propostas De} Atividades

Para entender o funcionamento das operações de adição e subtração, propomos o uso da atividade lúdica "nunca dez" com o uso de alguns ajaka e algumas pedrinhas para representar as unidades ${ }^{10}$. De início, devem-se pesquisar atividades do cotidiano dos Guarani que envolvam adições e subtrações. Apresentamos, como exemplo, as situações a seguir:

1. Considere que Alexandre, Anderson, Vanessa e Iara desejam comer 3 espigas de milhos cada um. Quantas espigas de milho serão comidas?

\section{Resolução sugerida:}

Na primeira etapa, conforme representado no Quadro 6, coloca-se três pedrinhas no ajaka 1, representando um conjunto de três espigas de milho de uma das pessoas.

\begin{tabular}{|l|l|}
\hline Ajaka 2 & Ajaka 1 \\
\hline & O O O \\
\hline
\end{tabular}

Quadro 6 : Número de espigas de milhos de uma pessoa Fonte: Silva (2011, p. 146)

Logo após, conforme representado no Quadro 7, coloca-se mais três conjuntos de três pedras no ajaka 1 representando três conjuntos de três espigas de milho das demais pessoas. Assim, ainda no ajaka 1 , temos a representação da quantidade de milhos das quatro pessoas.

${ }^{10}$ As duas próximas atividades são adaptações de Tinoco (2001, p. 246). 


\begin{tabular}{|c|c|}
\hline Ajaka 2 & Ajaka 1 \\
\hline \multirow{7}{*}{} & O O O \\
& O O O \\
& O O O \\
& O O O \\
\hline
\end{tabular}

Quadro 7: Número de espigas de milhos de todas as pessoas Fonte: Silva (2011, p. 146)

$\mathrm{Na}$ próxima etapa, definimos a regra "nunca dez". Dessa maneira, os ajaka ficam organizados conforme o quadro 8 a seguir.

\begin{tabular}{|c|c|}
\hline Ajaka 2 & Ajaka 1 \\
\hline $\mathrm{O}$ & $\mathrm{O} \mathrm{O}$ \\
\hline
\end{tabular}

Quadro 8 - "Nunca dez"

Fonte: Silva (2011, p. 147)

Finalmente, conclui-se que serão consumidas 12 espigas de milho. Na atividade seguinte, trabalha-se a operação de subtração.

2. Considere que Vanessa está vendendo um belo ajaka a uma senhora. Suponha que o ajaka custe $\mathrm{R} \$ 12,00$ e que a senhora entregue uma nota de R\$20,00 para Vanessa. Quantos reais Vanessa tem que devolver para a senhora?

\section{Resolução sugerida:}

Primeiramente representamos o dinheiro da senhora e o preço do ajaka vendido, conforme o quadro 9, a seguir ${ }^{11}$. Nessa figura, a primeira e a segunda linha representam, respectivamente, o dinheiro da senhora e o preço do ajaka.

\begin{tabular}{|c|c|}
\hline Ajaka 2 & Ajaka 1 \\
\hline $\mathrm{OO}$ & \\
$\mathrm{O}$ & $\mathrm{OO}$ \\
\hline
\end{tabular}

Quadro 9: Representação do dinheiro e do preço Fonte: Silva (2011, p. 147)

Como uma pedrinha no ajaka 2 equivale a dez do ajaka 1, pode-se ficar com a representação do quadro seguinte.

${ }^{11}$ Para essas atividades sugerimos o uso da base 10. 


\begin{tabular}{|l|l|}
\hline Ajaka 2 & Ajaka 1 \\
\hline $\mathrm{O}$ & OOOOOOOOOO \\
$\mathrm{O}$ & $\mathrm{OO}$ \\
\hline
\end{tabular}

Quadro 10 - Transformação de uma dezena para unidades Fonte: Silva (2011, p. 148)

Usando a operação de subtração, os cálculos serão feitos seguindo os quadros 11 e 12 a seguir.

\begin{tabular}{|c|c|}
\hline Ajak 2 & Ajaka 1 \\
\hline 0 & 0000000000 \\
0 & 00 \\
\hline
\end{tabular}

Quadro 11 - Operando a subtração Fonte: Silva (2011, p. 148)

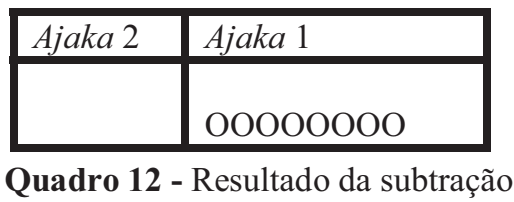

Fonte: Silva (2011, p. 148)

Depois de efetuados os cálculos, conclui-se que Vanessa deve devolver 8 reais para a senhora. Com a prática, os alunos podem entender o significado do vai um da adição e do empresta um da subtração.

\section{Considerações finais}

Apesar de os indígenas, tradicionalmente, possuírem seu próprio sistema de contagem, esses povos, por vezes, necessitam conhecer outros sistemas. Isso se deve ao fato, segundo Leal Ferreira (1998, p. 110, grifo da autora), de que "a situação de contato com a sociedade nacional, porém, obriga os povos indígenas a compreender o sistema de numeração decimal, da maneira como este sistema tem sido trabalhado no Brasil."

Entretanto, essa prática não deve ter o objetivo de mostrar que um conhecimento deve substituir o outro, a ideia é ampliar e não descartar o que o já se sabe. Dessa forma,

O domínio de duas etnomatemáticas, e possivelmente de outras, obviamente oferece maiores possibilidade de explicações, de entendimentos, de manejo de situações novas, de resolução de problemas. Mas é exatamente assim que se faz pesquisa em matemática - e na verdade em qualquer outro campo do conhecimento. $\mathrm{O}$ acesso a um maior número de instrumentos e de técnicas intelectuais dá, quando devidamente contextualizado, muito maior capacidade de enfrentar situações novas [...]. (D’AMBROSIO, 2005 p. 118)

O Programa Etnomatemática na Educação Escolar Indígena, de forma institucionalizada e intencional, pode transformar situações cotidianas em propostas pedagógicas. Essas situações, 
se devidamente contextualizadas e significadas, podem tanto estimular a revitalização da cultura indígena, através de pesquisas com a comunidade, quanto servir de ponto de partida para o entendimento de outros conhecimentos. Num debate contínuo entre as ideias tradicionais e as escolares, devem-se delimitar as semelhanças e diferenças de cada forma de conhecer, permitindo que seja identificado o contexto em que cada conhecimento está inserido. Assim, contribui-se para que os alunos ampliem sua forma de conhecer e lidar com o mundo. A matemática acadêmica pode contribuir para o entendimento da etnomatemática Guarani.

Ademais, a Etnomatemática, ao se inserir na Educação Escolar Indígena, lida com dois grandes desafios:

[...] preparar as populações indígenas para um convívio digno com a civilização dominante; e possibilitar aos povos indígenas a revitalização de sua identidade cultural. (FERREIRA, 1998, p. 12)

Em nosso contato com os Guarani percebemos que, de fato, esses desafios são grandes anseios desse povo e, por isso, elaboramos nossas propostas de atividades com o objetivo de contribuir para tais demandas. Porém, elas não devem ser encaradas como receitas fechadas e absolutas ou como uma solução definitiva para tais anseios. Neste sentido, o que pretendemos, conforme já dito, é apenas contribuir. Logo, fica a critério dos professores e interessados a utilização dessas propostas de maneira integral ou com modificações, dependendo apenas de sua compreensão e realidade.

De qualquer forma, na prática pedagógica vislumbramos que a etnomatemática Guarani pode ser articulada a matemática acadêmica.

\section{Referências}

ANDRÉ, M. E. D. A. Estudo de caso em pesquisa e avaliação educacional. Brasília: Líber Livro, 2008.

ANTUNES, A. Karai Tataendy. Palavras de um Xeromoi. Florianópolis: Cuca Fresca, 2008.

FERREIRA, E. S. A importância do conhecimento etnomatemático indígena na escola dos não-índios.

Em Aberto. Brasília, ano 14, $\mathrm{n}^{\circ}$ 62, p. 88-95, abr./jun. 1994.

FERREIRA, M.K. L. Madikauku. Os dez dedos da mão. Matemática e povos indígenas no Brasil. MEC/SEF, Brasília, 1998.

. A educação escolar indígena: um diagnóstico crítico da situação no Brasil. In: ARACY, L. S.; FERREIRA, M. K. L. (Org.). Antropologia, história e educação: a questão indígena e a escola. São Paulo: Global, 2001.

D'AMBROSIO, U. Etnomatemática - elo entre as tradições e a modernidade. 2. ed. $2^{\mathrm{a}}$ reimp. Belo Horizonte: Autêntica, 2005. 
. Posfácio. In: RIBEIRO, J. P. M.; DOMITE, M. C. S.; FERREIRA, R. Etnomatemática: papel, valor e significado. 2. ed. Porto Alegre: Zouk, 2006.

GUNDLACH, Bernard $\mathrm{H}$. Tópicos de história da matemática para uso em sala de aula. Trad. Hygino H. Domingues. São Paulo: Atual, 1992. v. 1.

SCANDIUZZI, P.P. Educação indígena x educação escolar indígena: uma relação etnocida em uma pesquisa etnomatemática. São Paulo: UNESP, 2009.

SILVA, Sérgio Florentino da. Sistema de numeração Guarani: caminhos para a prática pedagógica. 2011. 254 f. Dissertação (Mestrado em Educação Científica e Tecnológica) - Universidade Federal de Santa Catarina, Florianópolis, 2011.

TINOCO, S.L.S.M. "Nunca dez!” A matemática Karai-ko e o uso do ábaco entre os Waiãpi do Amapá. In: ARACY, L. S; FERREIRA, Mariana K. Leal. (org.). Práticas pedagógicas na escola indígena. São Paulo: Global, 2001. 